Available online at GSC Online Press Directory

GSC Biological and Pharmaceutical Sciences

e-ISSN: 2581-3250, CODEN (USA): GBPSC2

Journal homepage: https://www.gsconlinepress.com/journals/gscbps

(RESEARCH ARTICLE)

\title{
Measuring IGF-1 and IGFBP-3 profiles in women seeking assisted reproduction; relationship to ovarian reserve parameters, namely AFC and AMH (study 2).
}

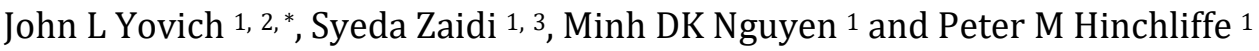 \\ ${ }^{1}$ PIVET Medical Centre Perth, Western Australia Australia 6007. \\ 2 Department of Pharmacy and Biomedical Sciences Curtin University Perth, Western Australia Australia 6845. \\ ${ }^{3}$ Department of Obstetrics and Gynaecology, Faculty of Medicine, University of Malaya Lembah Pantai, Kuala Lumpur \\ Malaysia 59100.
}

Publication history: Received on 01 October 2020; revised on 15 October 2020; accepted on 20 October 2020

Article DOI: https://doi.org/10.30574/gscbps.2020.13.2.0322

\begin{abstract}
This is the second of five studies undertaken on women preparing for assisted reproduction, to sequentially examine the relevance of the insulin-like growth factor (IGF) profile (IGF-1, IGFBP-3 and the IGFBP-3/ IGF-1 ratio) which, in children, provides the essential criteria to identify the GH-deficient individual. Whilst our first, published study, focussed on clinical parameters, this study examines its relevance to the two parameters which define the ovarian reserve. The first, that of the antral follicle count (AFC), shows highly significant, sequential changes across 4 age groups ranging from high counts in the younger women $<35$ years and low counts in the older women, namely those aged 35 39 years, those aged 40-44 years and those aged $\geq 45$ years $(\mathrm{p}<0.0001)$. Similarly, the serum levels of anti-Mullerian hormone $(\mathrm{AMH})$, a later introduced marker of ovarian reserve, also showed highly significant sequential changes across the 4 age groups with high levels recorded in the young women and low counts in the older women $(\mathrm{p}<0.0001)$. At the higher AFC range, concordance between AFC groups and AMH groups was high at $\mathrm{r}=0.79$ for precise matching and $\mathrm{r}=0.95$ when neighbouring groups were included. The correlation was also clear with inter-quartile AMH levels ranging $27 \mathrm{pmol} / \mathrm{L}$ to $50 \mathrm{pmol} / \mathrm{L}$ across the higher AFC groups and $8 \mathrm{pmol} / \mathrm{L}$ to $10 \mathrm{pmol} / \mathrm{L}$ in the lowest groupings. However, IGF profiles showed no significant variations across the entire range, neither for the AFC nor for the AMH groups. Our next study will report on the relevance of the IGF profile to clinical outcomes.
\end{abstract}

Keywords: Anti-Mullerian Hormone (AMH); Antral Follicle Count (AFC); Age Groups; Igf-1 Profile; IGFBP-3/ IGF-1 Ratio (IGF Ratio); Assisted Reproductive Technology (ART); In Vitro Fertilization (IVF); Growth Hormone (GH); PIVET FSH-Dosing Algorithm.

\section{Introduction}

In the 42 years since successful livebirths from in vitro fertilization (IVF) the field has progressed rapidly with more than 10 million infants arising from this and related areas of assisted reproductive technology (ART) [1,2]. Nonetheless, most of the successes have been enjoyed by younger women, whilst only a small component of those over age 40 years have achieved the benefits of ART, despite investing a much higher proportion of their time, their finances, and their energies (including emotional, physical and marital energy) into IVF-related attempts [3]. The ART facilities have introduced an array of clinical protocols, techniques and adjuvants for those women categorised as poor-prognosis, due mostly to the age-related decline in fertility, but which is sometimes caused by other, poorly defined factors. The extensive array of adjuvants applied in the poor-prognosis category attempting to redress the outcome disparity has been introduced in an empirical manner and it is currently difficult to know if the successes achieved in such poor-

\footnotetext{
${ }^{*}$ Corresponding author: John L Yovich
}

PIVET Medical Centre Perth, Western Australia Australia 6007.

Copyright (C) 2020 Author(s) retain the copyright of this article. This article is published under the terms of the Creative Commons Attribution Liscense 4.0. 
prognosis cases is fortuitous or treatment-related [4]. Whilst the vast majority of adjuvant therapies lack evidencebased support at this stage, one such adjuvant, namely growth hormone, has some supporting evidence [3,5,6]. Nonetheless, most GH trials have been given on an empirical basis, without any attempt to define adult growth hormone deficiency (AGHD) and this has drawn criticism [7]. Therefore, this study is the second in a series of studies to explore the concept of adult growth hormone deficiency (AGHD) underlying infertility with a defined poor-prognosis in current ART management. The idea is to explore those very same parameters which apply to the identification of GH-deficiency in children with low stature [8], to the adult female with infertility. Apart from the sequential measurement of stature and radiographic assessment of bone age, identifying the individual who should undergo provocative testing such as an Insulin sensitivity challenge, relies on serum screening of the Insulin-like Growth Factor (IGF) profile which includes IGF-1, its main binding protein IGFBP-3, and the IGF ratio of one against the other; our preference being IGFBP-3/ IGF1. Measuring human growth hormone (hGH) in serum collected during the day-time is considered unreliable. Such hGH levels are mostly very low because GH secretion from the pituitary is pulsatile and mostly nocturnal, disappearing rapidly from the serum [9]. Whereas our first study examined the IGF profile according to clinical parameters including age, body stature and body mass index [10], this second study examines the IGF profile in women attending for ART treatment and compares the measurements against tests for ovarian reserve, as women with lower reserve are considered to have higher likelihood for a poor prognosis.

\section{Material and methods}

This second study examines those same women who completed an Assessment Cycle (AC) at the PIVET centre for ART during the complete 9-year period from 2011 to 2019. As previously described this period embraces a highly stable program focusing on blastocyst culture ( 90\%), single embryo transfers (>95\%) and a strong focus on cryopreservation (exclusively undertaken with the Cryotop vitrification method) [11]. During this period 3751 women entered into 10,728 treatments of various ART categories. Figure 1 shows the derivation of 1633 women from a total 2319 women who had an Assessment Cycle (AC) and which included an IGF profile as well as an antral follicle count (AFC) estimation along with serum AMH testing. These measurements are fastidiously undertaken on all women in order to calculate their Follicle Stimulating Hormone (FSH) dosing schedule applying the PIVET Algorithm (Table 1) which has been well reported and validated over the past decade $[12,13]$. All these tests were performed around Day$5 \pm 1$ of the menstrual cycle, in the morning following a minimal "tea and toast" breakfast. Stature and BMI assessments were undertaken and reported in the first study [10] which correlated with the IGF profile assays. These ACs were oneoff evaluations of the underlying infertility factors and not repeated between ART treatments.

Table 1 One of the PIVET FSH-dosing Algorithms which have been applied throughout this study. They have been reported $[11,12,13]$ with validation indicating that $10 \pm 2$ oocytes are generated for the majority of women and ovarian hyperstimulation is uncommon at $<0.3 \%$.

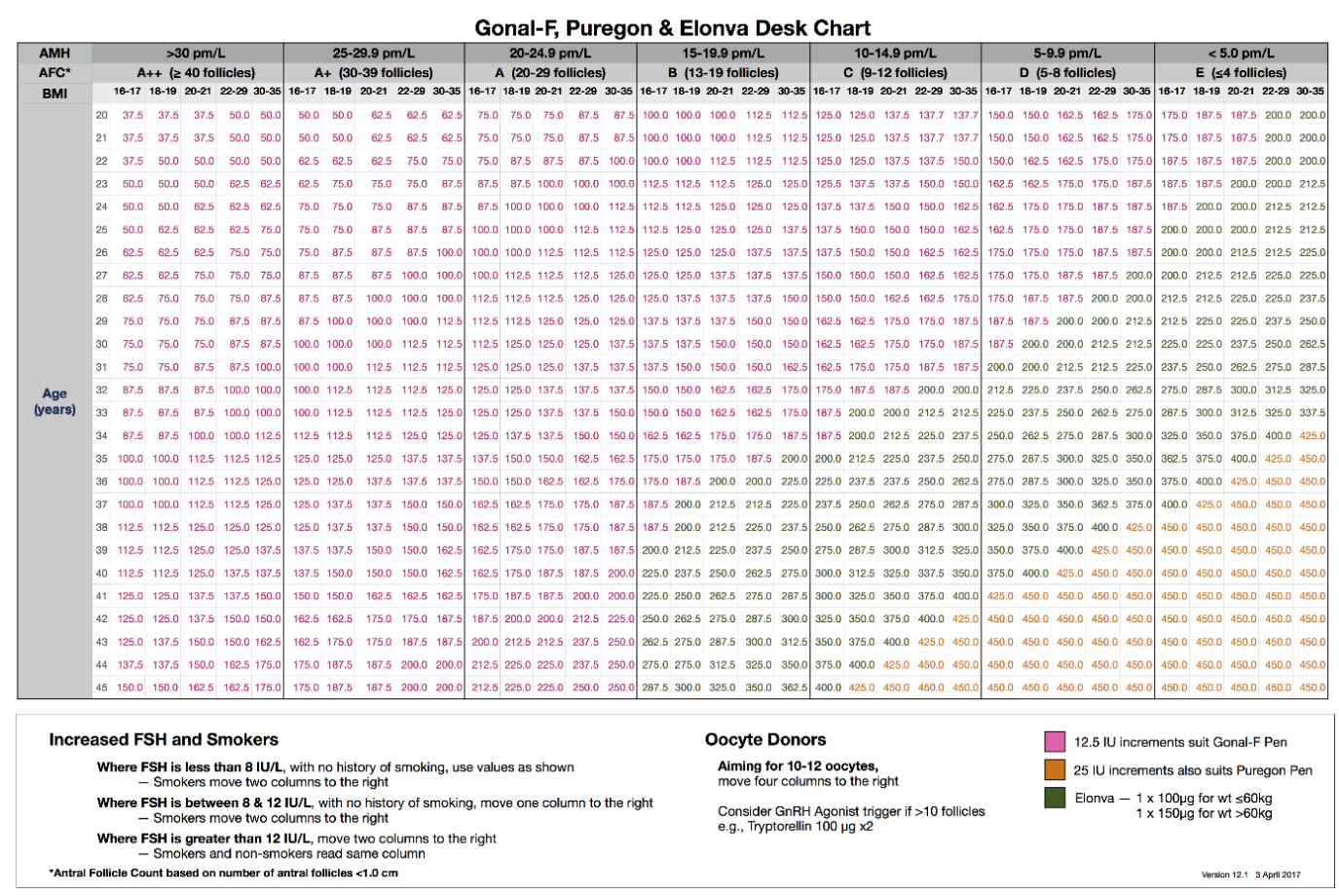




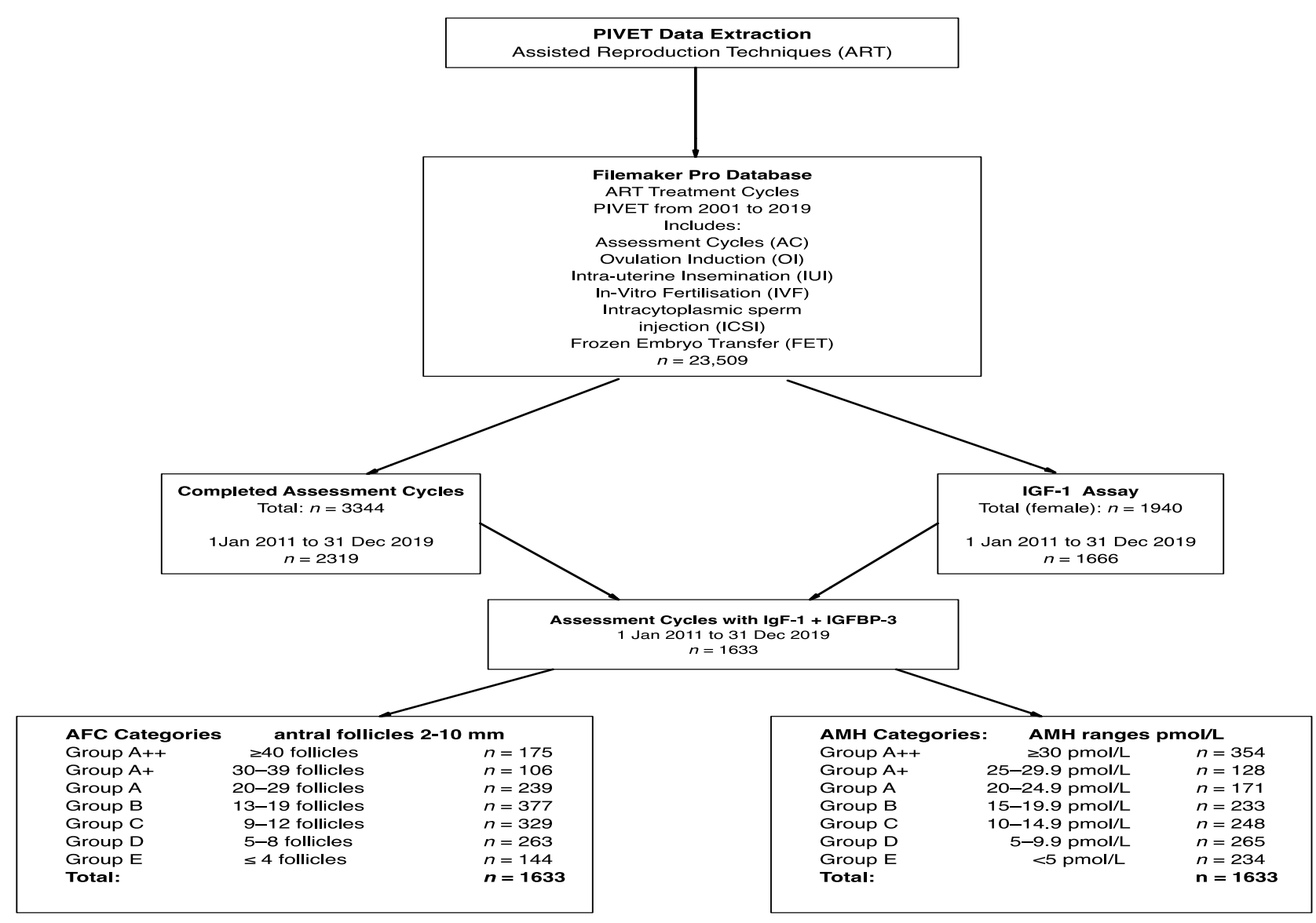

Figure 1 Flow diagram showing derivation of 1633 women who had an IGF profile (IGF-1 with IGFBP-3 and the IGF Ratio) in the early follicular phase of an Assessment Cycle undertaken prior to any definitive treatment. The distribution and ategorization of cases having antral follicle counts and anti-Mullerian hormone tests is also shown.

The additional evaluations undertaken in this second study are described as follows:

\subsection{AMH assays}

The earlier assays (2011 to 2016) were conducted on the Beckman Coulter Immunotech Gen 2 Elisa platform (Danaher Corporation; California, USA) and the data was correlated with AFC Groupings [14]. From 2017 the AMH assay has been performed on the Cobas Elecsys e411 platform (Roche Diagnostics; Basel, Switzerland). Both systems have been subject to tight quality assurance programs (RANDOX RIQAS) monitored under accreditation with the National Australian Testing Authority (NATA). We have found the results from both platforms to correlate well during the cross-over trials.

Blood specimens were collected in test tubes without EDTA; the samples are centrifuged at $\sim 1200 \mathrm{~g}$ for 15 minutes within 5 minutes of the collection. The serum is stored at $-20^{\circ} \mathrm{C}$ for batch processing each week. High supplemental biotin intake ( $>5 \mathrm{mg} /$ day) precludes undertaking the assay. The Cobas Elecsys assay is completed in $18 \mathrm{mins}$ applying a Sandwich technique. The first incubation utilises a $50 \mu \mathrm{L}$ serum sample and applies a biotinylated monoclonal AMHspecific antibody along with a monoclonal AMH-specific antibody labelled with a ruthenium complex to form the sandwich complex. The second incubation involves the addition of streptavidin-coated microparticles ensuring the ruthenium complex becomes bound to the solid phase via interaction of biotin and streptavidin. The reaction mixture is aspirated into the measuring cell where the microparticles are magnetically captured onto the surface of the electrode. Unbound substances are then removed with ProCell/ProCell M. Application of voltage to the electrode then induces a chemiluminescent emission which is measured by a photomultiplier. This assay has a detection limit of 1 $\mathrm{pmol} / \mathrm{L}$ with the coefficients of variation (CVs) for both intra-assay and inter-assay ranging 8-12\%. The results are determined from a calibration curve which is specifically generated by 2-point calibration from the instrument using a master curve provided with a reagent barcode. The assays are performed along with controls and rejected if outside the acceptable range ( $<20 \%$ intermediate precision) translating to a detection limit of $1.2 \mathrm{pmol} / \mathrm{L}$. 


\subsection{AFC determination}

AFCs were undertaken by trans-vaginal ultrasound using Voluson machines supplied from General Electric Australia; initially using the Voluson 730 Expert for 5-years, followed by the Voluson P6 in the most recent 4-years. The ovary is viewed in 3 planes for 2-D scanning and all detectable (antral) follicles up to $10 \mathrm{~mm}(2-10 \mathrm{~mm})$ are counted from both ovaries (a single ovary if the other is absent). According to the PIVET Algorithm shown in Table 1 the AFC is categorised as Grade A if $\geq 20$ antral follicles are counted. This grouping is sub-categorised as Grade A+ for 30-39 antral follicles and Grade A++ if $\geq 40$ antral follicles are counted. For antral follicle counts 13-19, the classification is Group B, for 9-12 the classification is Group C, for 5-8 the classification is Grade D and the lowest category is Grade E comprising $\leq 4$ antral follicles. Over the 9-year period these AFCs were undertaken by various technicians, nurses and doctors and, although the various scanners had all completed appropriate training, the counts were therefore considered an approximation, hence the data was presented in the aforementioned categorical manner.

\subsection{Statistical analysis}

Data extractions from the Filemaker database were placed in Microsoft Excel spreadsheets and sorted according to the relevant tests. Thereafter the sorted data was placed in the application Past 4.03 (developed by Øyvind Hammer) [15] for statistical data analysis. This application also generated the Tables comprising the statistical summaries, finally placed in Microsoft Word for clearer display. Having demonstrated in Study 1 that the data comprising the IGF profile (IGF-1, IGFBP-3 and IGF Ratio) are all distributed in a Normal fashion (10), the relationship among the means was examined by one-way ANOVA for overall comparison. The data concerning AMH, albeit continuous and shown in Figure 2 , are clearly not distributed in a Normal distribution, and AFC data are categorical as shown in Table 1, hence nonparametric analyses were applied. Both Mann-Whitney and Tukey's pair-wise plots compared the individual means which ranged from three (in percentile studies of stature) to eight (in BMI comparisons) for various analyses. The Kruskal-Wallis test was applied to examine equality between sample medians. For probability values, $\mathrm{p}<0.05$ was considered significant for any test. The Past 4.03 application also generated the Figures which were then upgraded in the xDiagram 5.4 application (developed by Vu Tien Thinh) enabling optimal display for this publication.

\section{Results}

Here we are reporting in SI units (Système Internationale; International System) as these are applied in our clinical practice. The conversion of SI units nmol/L to conventional mass units (ng/mL) is 7.65; hence $25 \mathrm{nmol} / \mathrm{L}$ can be read as $191 \mathrm{ng} / \mathrm{mL}$. This conversion factor applies for both IGF-1 and IGFBP-3. For AMH the conversion from mass units $(\mathrm{ng} / \mathrm{mL}$ or $\mu \mathrm{g} / \mathrm{L}$ ) to SI units (pmol/L) is 7.14 hence AMH $5 \mathrm{ng} / \mathrm{mL}(5 \mu \mathrm{g} / \mathrm{L})$ can be read as $35.7 \mathrm{pmol} / \mathrm{L}$.

The derivation of the 1633 women who had an IGF profile (IGF-1 with IGFBP-3 and the IGF Ratio) in the early follicular phase of an $\mathrm{AC}$ undertaken prior to any definitive treatment has been described in the methodology section. Figure 1 also shows the distribution and categorization of women having AFCs and AMH tests.

\subsection{AMH profile}

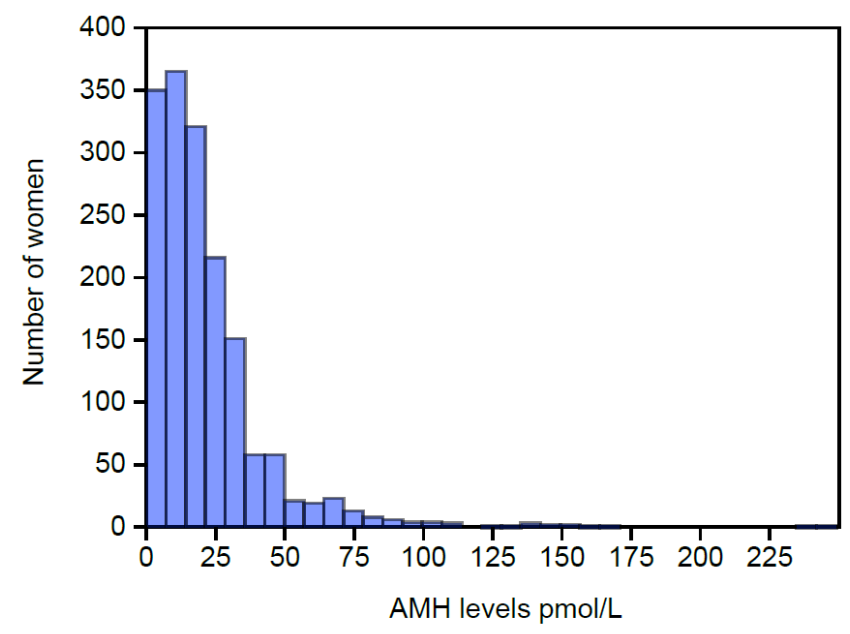

Figure 2 Displays a histogram derived from Table 2 showing the overall AMH profile for those 1633 women who completed the Assessment Cycle which included an IGF Profile. 
Table 2 Shows the summary statistics of the AMH distribution for the 1633 women who completed an Assessment Cycle with an IGF profile prior to any definitive ART treatment.

\begin{tabular}{|l|l|}
\hline AMH Distribution pmol/L \\
\hline N (women) & 1633 \\
\hline Min AMH level & $\leq 1$ \\
\hline Max AMH level & 249 \\
\hline Sum & 34829.2 \\
\hline Mean & 21.3 \\
\hline Std. error & 0.5 \\
\hline Variance & 469.4 \\
\hline Stand. dev & 21.7 \\
\hline Median & 15.5 \\
\hline 25th centile & 8 \\
\hline 75th centile & 27 \\
\hline Skewness & 3.5 \\
\hline Kurtosis & 2409.9 \\
\hline Geom. mean & 0 \\
\hline Coeff. var & 101.6 \\
\hline
\end{tabular}

The AMH profile displays a very wide range from undetectable or uncertain detection from $\leq 1 \mathrm{pmol} / \mathrm{L}$ to a maximal 249 $\mathrm{pmol} / \mathrm{L}$ although the majority of women showed levels between $8 \mathrm{pmol} / \mathrm{L}$ and $27 \mathrm{pmol} / \mathrm{L}$ being the inter-quartile range. Although the mean level was $21.3 \mathrm{pmol} / \mathrm{L}$, there is a large positive skewness hence the median position was found at $15.5 \mathrm{pmol} / \mathrm{L}$. Pearson's skewness is factored at 3.5, hence the profile is outside a Normal distribution and is displayed in Figure 2 as a histogram. Clearly the profile does not fit a Normal distribution hence the studies presented here are undertaken with categorical groupings.

\subsection{AFC vs age groups}

Table 3 Shows summary statistics for the AFC groupings of the 1633 women stratified according to the number from each age group (Table $3 \mathrm{a}$ ) along with calculation of the percentages for each age group (Table $3 \mathrm{~b}$ ).

\section{Table 3a}

\begin{tabular}{|l|l|l|l|l|}
\hline \multicolumn{6}{|l|}{ AFC Distribution (number of women) in Each Age Group (Gp) } \\
\hline Age & $<35$ years & $35-39$ years & $40-44$ years & $\geq 45$ years \\
\hline N (AFC Groups) & x3 AFC Groups & x3 AFC Groups & x3 AFC Groups & x3 AFC Groups \\
\hline Min & 137 in D\&E Gps & 96 in A Gps & 17 in A Gps & 2 in A Gps \\
\hline Max & 405 in A Gps & 215 in B\&C Gps & 110 in B\&C Gps & 32 in D\&E Gps \\
\hline Sum & 929 & 439 & 220 & 45 \\
\hline Mean & 309.7 & 146.3 & 73.3 & 15.0 \\
\hline Std. error & 86.5 & 35.6 & 28.6 & 8.9 \\
\hline Variance & 22441.3 & 3792.3 & 2452.3 & 237.0 \\
\hline Stand. dev & 149.8 & 61.6 & 49.5 & 15.4 \\
\hline
\end{tabular}




\begin{tabular}{|l|l|l|l|l|}
\hline Median & 387 & 128 & 93 & 11 \\
\hline $25^{\text {th }}$ centile & 137 & 96 & 17 & 2 \\
\hline $75^{\text {th }}$ centile & 405 & 215 & 110 & 32 \\
\hline Skewness & -1.7 & 1.2 & -1.5 & 1.1 \\
\hline Kurtosis & -2.3 & -2.3 & -2.3 & -2.3 \\
\hline Geom. mean & 277.9 & 138.2 & 55.8 & 8.9 \\
\hline Coeff. var & 48.4 & 42.1 & 67.5 & 102.6 \\
\hline
\end{tabular}

Table 3b

\begin{tabular}{|l|l|l|l|l|}
\hline \multicolumn{6}{|l|}{ AFC Distribution (number of women) in Each Age Group } \\
\hline Age & $<35$ years & $35-39$ years & $40-44$ years & $\geq 45$ years \\
\hline AFC: A Groups (n) & 405 & 96 & 17 & 2 \\
\hline AFC: B\&C Groups (n) & 387 & 215 & 110 & 11 \\
\hline AFC: D\&E Groups (n) & 137 & 128 & 93 & 32 \\
\hline Total women & 929 & 439 & 220 & 45 \\
\hline AFC Distribution (percentages) in Each Age Group & \multicolumn{2}{l|}{} \\
\hline AFC: A Groups \% & $44 \%$ & $22 \%$ & $8 \%$ & $4 \%$ \\
\hline AFC: B\&C Groups \% & $42 \%$ & $49 \%$ & $50 \%$ & $24 \%$ \\
\hline AFC: D\&E Groups \% & $15 \%$ & $29 \%$ & $42 \%$ & $71 \%$ \\
\hline
\end{tabular}

The distribution indicates that the younger women had a higher proportion of AFC Groups in the "A" categories and this proportion diminished sequentially and significantly in a linear fashion with the higher age categories $(\mathrm{p}<0.001)$. Conversely, the proportion of women having the lower AFC Groups ("D\&E" categories) rose sequentially and significantly in a linear fashion with the advanced age categories $(\mathrm{p}<0.0001)$. Figure 3 depicts a pie chart of this data showing the proportion with various AFC groupings according to their age categories.
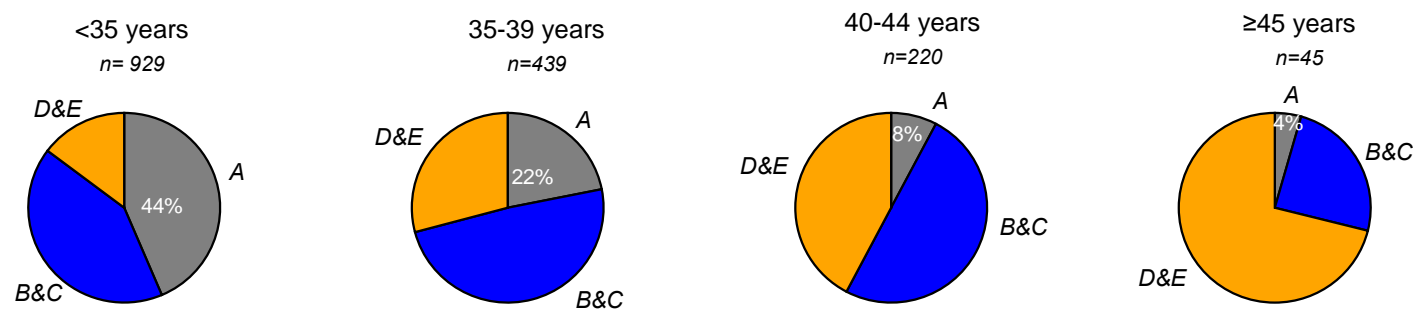

AFC Distributions for Age Groups

Figure 3 Depicts a pie chart of the 1633 women who completed an Assessment Cycle prior to any ART treatments, showing the proportion of women with various AFC groupings according to their Age categories.

The majority of women were in the young group aged $<35$ years, with $44 \%$ having AFC gradings within the "A" categories. This proportion of A Groups declined in a linear fashion to just $4 \%$ in the oldest age group ( $\geq 45$ years), albeit the number of women in this age category was only 45 cases, also demonstrating a significant linear decline, being only $3 \%$ of the total. Conversely, the proportion of women with the lower AFC groups rose in a linear fashion to be highest in the oldest age category $(\mathrm{p}<0.001)$. Within the middle two age groups covering ages 35 to 44 years, the AFC categories of $\mathrm{B} \& \mathrm{C}$ remained stable at $\sim 50 \%$ of cases. 


\subsection{AMH vs age groups}

Table 4 Displays the summary statistics for AMH levels of the 1633 women stratified according to age groups and which is further depicted in Figure 4.

\begin{tabular}{|l|l|l|l|l|}
\hline \multicolumn{6}{|l}{ AMH Distribution pmol/L vs Age Group } & \multicolumn{4}{l|}{ (35-39 years } & $40-44$ years & $\geq 45$ years \\
\hline Age groups & $<35$ years & 439 & 220 & 45 \\
\hline N (women) & 928 & $\leq 1$ & $\leq 1$ & $\leq 1$ \\
\hline Min AMH level & $\leq 1$ & 86.2 & 133 & 28.7 \\
\hline Max AMH level & 249 & 7291.7 & 2228.6 & 219.8 \\
\hline Sum & 25080.5 & 16.6 & 10.1 & 4.9 \\
\hline Mean & 27.0 & 0.7 & 0.8 & 0.7 \\
\hline Std. error & 0.8 & 192.8 & 152.4 & 25.0 \\
\hline Variance & 612.1 & 13.9 & 12.3 & 5.0 \\
\hline Stand. dev & 24.7 & 12.7 & 7.15 & 3.7 \\
\hline Median & 21.4 & 7.47 & 3 & 1.75 \\
\hline $25^{\text {th }}$ centile & 12.825 & 21.8 & 12.85 & 6.9 \\
\hline $75^{\text {th }}$ centile & 32.3 & 1.8 & 5.3 & 2.7 \\
\hline Skewness & 3.3 & 4.5 & 45.6 & 10.8 \\
\hline Kurtosis & 18.1 & 0.0 & 6.1 & 2.6 \\
\hline Geom. mean & 0.0 & 83.6 & 121.9 & 102.4 \\
\hline Coeff. var & 91.5 & & & \\
\hline
\end{tabular}

It can be seen that AMH levels show a linear reduction in both the mean and the median levels with advancing age groups $(\mathrm{p}<0.001)$. However, the variance is very wide, particularly in the youngest group $<35$ years. In all groups the minimum AMH level was at the detectable /uncertain detection level of $\leq 1 \mathrm{pmol} / \mathrm{L}$. Figure 4 displays the AMH levels as Bar Charts with standard errors depicted across the 4 age categories.

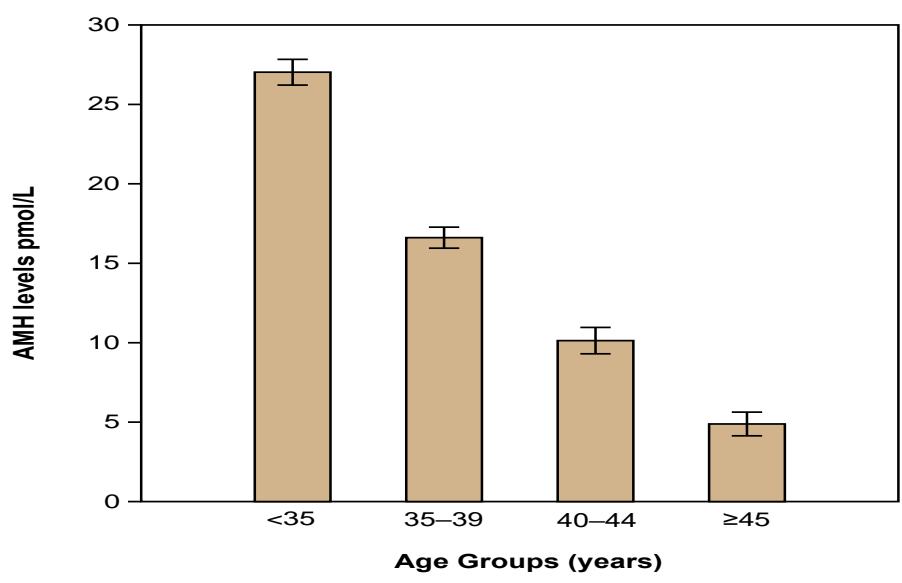

Figure 4 Displays the AMH levels as bar charts with standard errors depicted across the 4 age categories.

As noted in Table 4 the standard errors were relatively small at $<0.8$ across the groups. The significant linear reduction in AMH levels with advancing age is clearly shown $(\mathrm{p}<0.001)$. In the youngest age group, the mean level was 27.0 
$\mathrm{pmol} / \mathrm{L}$, reducing to $16.6 \mathrm{pmol} / \mathrm{L}$ in the range of 35-39 years, then $10.1 \mathrm{pmol} / \mathrm{L}$ in the group aged 40-44 years and finally at $4.9 \mathrm{pmol} / \mathrm{L}$ in the most advanced age group $\geq 45$ years.

\subsection{AMH vs AFC concordance}

Table 5 Displays the AMH levels according to AFC categories which have been grouped according to the combined A groups (comprising $\mathrm{A}++, \mathrm{A}+, \mathrm{A}$ ), the combined $\mathrm{B} \& \mathrm{C}$ groups and the combined $\mathrm{D} \& \mathrm{E}$ groups.

\begin{tabular}{|l|l|l|l|}
\hline AMH levels pmol/L vs AFC Groups & B\&C & D\&E \\
\hline AFC Groups & A++, A+, A & 705 & 407 \\
\hline N & 519 & $\leq 1$ & $\leq 1$ \\
\hline Min & $\leq 1$ & 133 & 62.1 \\
\hline Max & 249 & 11935.5 & 3912.1 \\
\hline Sum & 18964.6 & 16.9 & 9.6 \\
\hline Mean & 36.5 & 0.5 & 0.5 \\
\hline Std. error & 1.3 & 151.4 & 110.0 \\
\hline Variance & 820.4 & 12.3 & 10.5 \\
\hline Stand. dev & 28.6 & 14.7 & 6 \\
\hline Median & 28.1 & 9.3 & 3 \\
\hline $25^{\text {th }}$ centile & 21 & 20.85 & 12 \\
\hline $75^{\text {th }}$ centile & 43.1 & 2.5 & 2.2 \\
\hline Skewness & 3.0 & 13.5 & 5.3 \\
\hline Kurtosis & 13.4 & 0.0 & 5.5 \\
\hline Geom. mean & 0.0 & 72.7 & 109.1 \\
\hline Coeff. var & 78.4 & & \\
\hline
\end{tabular}

It can be seen that the mean AMH levels in these categories decrease significantly from the high AFC category A groups to the lowest D\&E groups ( $\mathrm{p}<0.001)$. These mean levels are slightly higher than the median levels, consistent with some degree of skewness ranging from 3.0 down to 2.2 at the lower AFC grouping. This data has been used to develop Figure 5 .

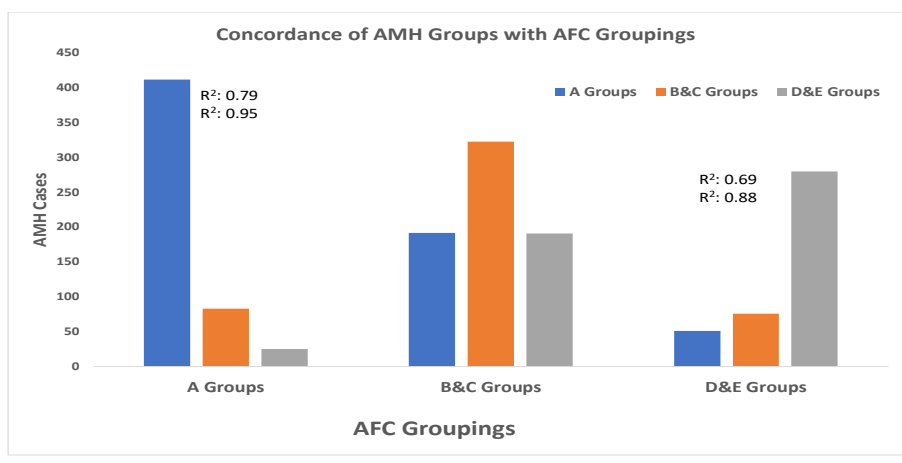

Figure 5 Shows bar charts to depict the level of concordance between AMH and AFC categories, each represented by their defined groups. 
By comparing the matching of $\mathrm{AMH}$ cases against $\mathrm{AFC}$ groups, it can be seen that the concordance $\left(\mathrm{R}^{2}\right)$ of $\mathrm{AMH}$ to $\mathrm{AFC}=$ 0.79 for precise A group matching and rises to 0.95 when the neighboring groups (B\&C) are included. At the lower end, the $\mathrm{AMH}$ groups match the AFC groups $\mathrm{D} \& \mathrm{E}$ with $\mathrm{R}^{2}$ at 0.69 for precise matching, rising 0.88 when the neighboring groups $(B \& C)$ are included.

\subsection{AMH and AFC correlation}

Table 6 Shows the correlation between AMH and AFC for the 1633 women in the study. The summary statistics are shown in Table $6 \mathrm{a}$ and the respective coefficients of correlation are shown in Table $6 \mathrm{~b}$.

\section{Table 6a}

Table 6b

\begin{tabular}{|l|l|l|l|l|l|l|l|}
\hline \multicolumn{7}{|l}{ AMH levels pmol/L vs AFC Groups } \\
\hline AFC Group & A++ & A+ & A & B & C & D & E \\
\hline N (women) & 175 & 106 & 238 & 376 & 330 & 263 & 144 \\
\hline Min & 0 & 6.8 & 0 & 0 & 0.7 & 0.1 & 0.07 \\
\hline Max & 249 & 163.9 & 142.5 & 78.4 & 133 & 62.1 & 58.2 \\
\hline Sum & 8738.3 & 3838.3 & 6388.0 & 6967.9 & 4976.1 & 2743.9 & 1168.2 \\
\hline Mean & 49.9 & 36.2 & 26.8 & 18.5 & 15.1 & 10.4 & 8.1 \\
\hline Std. error & 2.8 & 2.3 & 1.2 & 0.6 & 0.7 & 0.6 & 0.9 \\
\hline Variance & 1357.8 & 559.0 & 321.5 & 142.4 & 155.4 & 109.7 & 107.9 \\
\hline Stand. dev & 36.8 & 23.6 & 17.9 & 11.9 & 12.5 & 10.5 & 10.4 \\
\hline Median & 38.5 & 27.7 & 22 & 15.9 & 11.8 & 7 & 3.5 \\
\hline 25th centile & 31.4 & 22 & 18 & 10.9 & 8.8 & 4 & 1.9 \\
\hline $75^{\text {th }}$ centile & 59.9 & 42.9 & 30.8 & 23.1 & 17.6 & 12.2 & 10.6 \\
\hline Skewness & 2.5 & 2.4 & 2.6 & 1.6 & 3.7 & 2.2 & 2.1 \\
\hline Kurtosis & 8.9 & 7.9 & 10.2 & 3.7 & 25.6 & 5.8 & 5.0 \\
\hline Geom. mean & 0.0 & 31.0 & 0.0 & 0.0 & 11.6 & 6.6 & 3.9 \\
\hline Coeff. var & 73.8 & 65.3 & 66.8 & 64.4 & 82.7 & 100.4 & 128.0 \\
\hline
\end{tabular}

\begin{tabular}{|l|l|l|l|l|l|l|l|}
\hline \multicolumn{7}{|l}{ AMH Groups pmol/L vs AFC Groups } \\
\hline AFC Group & A++ & A+ & A & B & C & D & E \\
\hline AMH Group A++ & & 0.82 & 0.95 & 0.03 & 0.52 & 0.91 & 0.42 \\
\hline AMH Group A+ & -0.02 & & 0.33 & 0.28 & 0.31 & 0.27 & 0.95 \\
\hline AMH Group A & -0.01 & -0.10 & & 0.88 & 0.93 & 0.93 & 0.62 \\
\hline AMH Group B & 0.17 & 0.11 & -0.01 & & 0.53 & 0.54 & 0.77 \\
\hline AMH Group C & 0.05 & 0.10 & -0.01 & 0.04 & & 0.72 & 0.75 \\
\hline AMH Group D & 0.01 & -0.11 & -0.01 & 0.04 & -0.02 & & 0.01 \\
\hline AMH Group E & -0.07 & 0.01 & -0.04 & -0.02 & -0.03 & 0.21 & \\
\hline
\end{tabular}

Table 6a shows the AMH levels according to each AFC grouping. It can be seen that the highest ranges occur in the A groups, albeit that the lowest levels ( $\leq 1 \mathrm{nmol} / \mathrm{L}$ ) occur in all AFC groups. The mean levels are similar, albeit slightly higher than the median levels, in each AFC group, reflecting the skewness ratings between 1.6 to 3.7 across the AFC range. The mean $A M H$ levels decline in a linear and highly significant fashion from $49.9 \mathrm{pmol} / \mathrm{L}$ in the highest $\mathrm{AFC}$ group $\mathrm{A}++$ to $8.1 \mathrm{pmol} / \mathrm{L}$ in the lowest AFC group $\mathrm{E}(\mathrm{p}<0.001)$ and this data is represented in Figure 6 . The individual univariate correlations between the AMH and AFC groupings is depicted in Table $6 \mathrm{~b}$ which shows Pearson's correlation coefficient $r$ for respective groupings. The closer the $r$ value is to \pm 1 , the relationship between the groups is close whilst the closer 
the $\mathrm{r}$ value is to 0 , the more disparate are the groups. The positive correlations are shown in the upper right region of Table $6 \mathrm{~b}$. With matching groups, the correlations are mostly close to each other and near to 1; whilst disparate groups are closer to 0 .

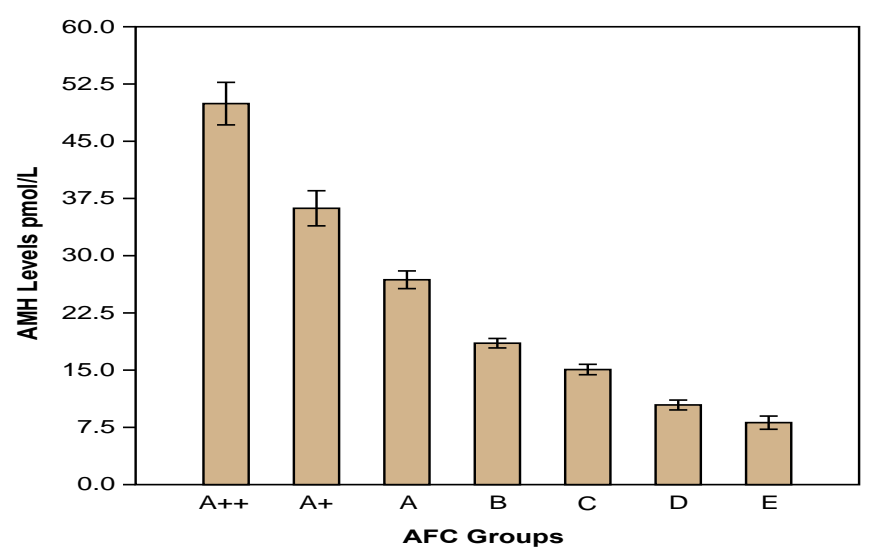

Figure 6 Depicts a bar chart derived from Table 6a, correlating AMH levels with AFC groupings for the 1633 women.

It can be seen that the mean \pm SEM of AMH levels decline in accordance with AFC Groups in a steady, highly significant linear fashion $(\mathrm{p}<0.001)$. This means that AMH levels decline to their lowest (mean 8.1pmol/L) as the AFC groups display lower levels ( $<5$ antral follicles). Furthermore, the SEM range becomes tighter with this decline, reducing as the AFC groups progress to the lowest scale which represents a smaller, diminished ovarian reserve (D\&E).

\subsection{IGF profile vs AFC}

Table 7 Displays summary statistics for the 1633 women with IGF profiles stratified according to their AFC groups and depicted in Figure 7. The IGF-1 distribution is shown in Table 7a, the IGFBP-3 distribution in Table $7 \mathrm{~b}$ and the distribution of IGF ratios is shown in Table 7c.

\section{Table 7a}

\begin{tabular}{|l|l|l|l|l|l|l|l|}
\hline \multicolumn{7}{|l}{ IGF-1 nmol/L vs AFC Groups } \\
\hline AFC Group & A++ & A+ & A & B & C & D & E \\
\hline N (women) & 239 & 87 & 126 & 170 & 180 & 199 & 245 \\
\hline Min & 9 & 10 & 13 & 10 & 12 & 10 & 10 \\
\hline Max & 50 & 42 & 44 & 48 & 49 & 48 & 63 \\
\hline Sum & 6032 & 2216 & 3245 & 4292 & 4767 & 5094 & 6169 \\
\hline Mean & 25.2 & 25.5 & 25.8 & 25.2 & 26.5 & 25.6 & 25.2 \\
\hline Std. error & 0.5 & 0.7 & 0.6 & 0.6 & 0.5 & 0.5 & 0.5 \\
\hline Variance & 48.9 & 41.0 & 47.7 & 53.1 & 47.2 & 40.7 & 52.8 \\
\hline Stand. dev & 7.0 & 6.4 & 6.9 & 7.3 & 6.9 & 6.4 & 7.3 \\
\hline Median & 25 & 26 & 25 & 24 & 26 & 25 & 24 \\
\hline 25th centile & 21 & 22 & 21 & 20 & 22 & 21 & 21 \\
\hline $75^{\text {th }}$ centile & 29 & 29 & 30 & 29 & 31 & 29 & 29 \\
\hline Skewness & 0.5 & 0.0 & 0.3 & 0.6 & 0.5 & 0.4 & 1.0 \\
\hline Kurtosis & 0.5 & 0.0 & -0.3 & 0.5 & 0.2 & 0.4 & 3.1 \\
\hline Geom. mean & 24.3 & 24.6 & 24.8 & 24.2 & 25.6 & 24.8 & 24.2 \\
\hline Coeff. var & 27.7 & 25.1 & 26.8 & 28.9 & 25.9 & 24.9 & 28.9 \\
\hline
\end{tabular}


Table 7b

Table 7c

\begin{tabular}{|l|l|l|l|l|l|l|l|}
\hline \multicolumn{7}{|l}{ IGFBP-3 nmol/L vs AFC Groups } \\
\hline AFC Group & A++ & A+ & A & B & C & D & E \\
\hline N (women) & 175 & 106 & 239 & 377 & 329 & 263 & 144 \\
\hline Min & 89 & 108 & 94 & 59 & 77 & 66 & 95 \\
\hline Max & 259 & 237 & 265 & 256 & 270 & 263 & 247 \\
\hline Sum & 29716 & 17819 & 40969 & 62251 & 55667 & 44045 & 23285 \\
\hline Mean & 169.8 & 168.1 & 171.4 & 165.1 & 169.2 & 167.5 & 161.7 \\
\hline Std. error & 2.3 & 3.0 & 1.8 & 1.4 & 1.7 & 1.9 & 2.3 \\
\hline Variance & 947.0 & 957.3 & 751.5 & 780.4 & 926.0 & 971.6 & 734.2 \\
\hline Stand. dev & 30.8 & 30.9 & 27.4 & 27.9 & 30.4 & 31.2 & 27.1 \\
\hline Median & 169 & 168 & 171 & 163 & 167 & 168 & 160.5 \\
\hline 25 $5^{\text {th }}$ centile & 148 & 145 & 151 & 146 & 150 & 149 & 143 \\
\hline $75^{\text {th }}$ centile & 189 & 189 & 189 & 182 & 187 & 188 & 178 \\
\hline Skewness & 0.3 & 0.2 & 0.3 & 0.3 & 0.3 & -0.1 & 0.3 \\
\hline Kurtosis & 0.2 & -0.5 & 0.3 & 0.7 & 0.5 & 0.5 & 0.3 \\
\hline Geom. mean & 167.0 & 165.3 & 169.2 & 162.7 & 166.5 & 164.3 & 159.4 \\
\hline Coeff. var & 18.1 & 18.4 & 16.0 & 16.9 & 18.0 & 18.6 & 16.8 \\
\hline
\end{tabular}

\begin{tabular}{|l|l|l|l|l|l|l|l|}
\hline \multicolumn{2}{|l}{ IGFBP-3/ IGF-1 Ratio vs AFC Groups } \\
\hline AFC Group & A++ & A+ & A & B & C & D & E \\
\hline N (women) & 175 & 106 & 240 & 377 & 329 & 263 & 143 \\
\hline Min & 4 & 2.5 & 3.6 & 3.3 & 3.3 & 2.6 & 3.6 \\
\hline Max & 11.6 & 11.1 & 14.2 & 15.6 & 16.8 & 20.4 & 14.8 \\
\hline Sum & 1190.7 & 702 & 1630 & 2493 & 2302.9 & 1935 & 1030.7 \\
\hline Mean & 6.8 & 6.6 & 6.8 & 6.6 & 7.0 & 7.4 & 7.2 \\
\hline Std. error & 0.1 & 0.2 & 0.1 & 0.1 & 0.1 & 0.1 & 0.1 \\
\hline Variance & 2.7 & 2.6 & 2.7 & 2.6 & 3.1 & 5.0 & 2.8 \\
\hline Stand. dev & 1.6 & 1.6 & 1.7 & 1.6 & 1.8 & 2.2 & 1.7 \\
\hline Median & 6.6 & 6.3 & 6.4 & 6.3 & 6.7 & 7 & 7.1 \\
\hline 25th centile & 5.5 & 5.6 & 5.7 & 5.5 & 5.8 & 6 & 6.1 \\
\hline $75^{\text {th }}$ centile & 7.8 & 7.7 & 7.6 & 7.4 & 7.8 & 8.4 & 8.2 \\
\hline Skewness & 0.8 & 0.4 & 1.3 & 1.3 & 1.4 & 1.7 & 0.8 \\
\hline Kurtosis & 0.2 & 0.3 & 2.4 & 3.7 & 4.0 & 5.8 & 2.1 \\
\hline Geom. mean & 6.6 & 6.4 & 6.6 & 6.4 & 6.8 & 7.1 & 7.0 \\
\hline Coeff. var & 24.0 & 24.4 & 24.3 & 24.3 & 25.2 & 30.4 & 23.3 \\
\hline
\end{tabular}




\section{Figure 7a}

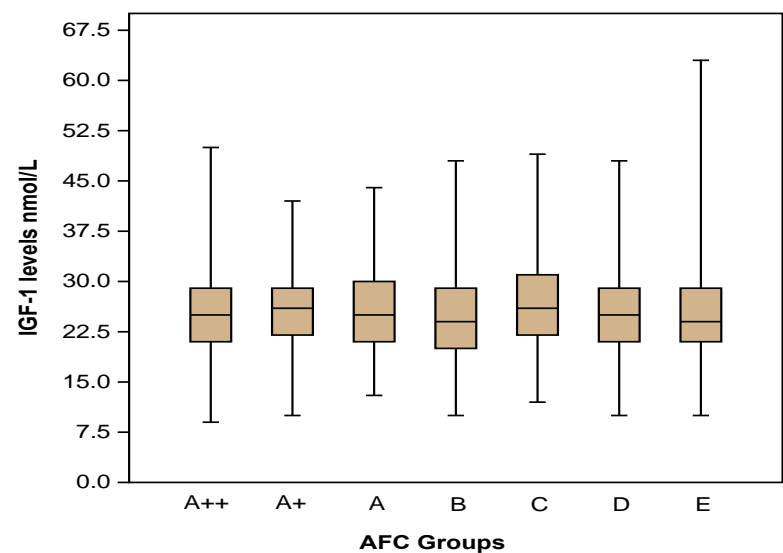

Figure 7b

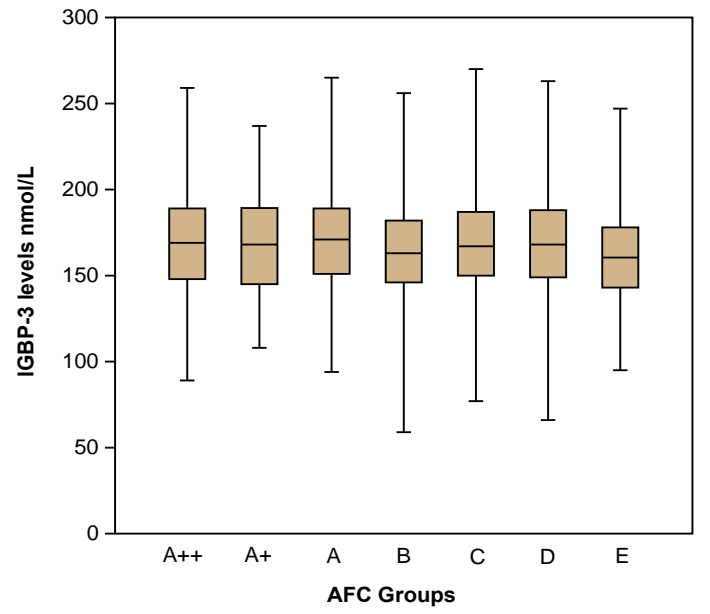

Figure 7c

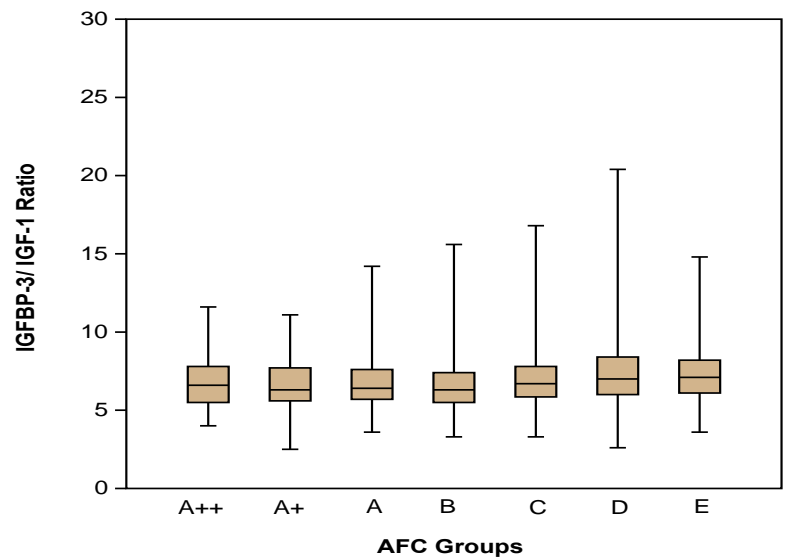

Figure 7 Shows a box plot depiction of the IGF profile across the range of AFC groups; IGF-1 in Figure 7a, IGFBP-3 in Figure $7 \mathrm{~b}$ and IGF Ratio in Figure 7c. 
The IGF-1 levels are shown for seven AFC categories ranging from the highest at Group A++ with $\geq 40$ small antral follicles to the lowest at Group E with $\leq 4$ small antral follicles. Table 7a covers the IGF- 1 component of the IGF profile. It can be seen that both mean and median IGF-1 levels are similar at $\sim 25 \mathrm{nmol} / \mathrm{L}$. This is consistent with a Normal Distribution for IGF-1 which was shown in Study 1 [10]. There is minimal skewness, and the inter-quartile range is quite narrow across the groups, being mostly $21 \mathrm{nmol} / \mathrm{L}$ to $29 \mathrm{nmol} / \mathrm{L}$ with no significant differences across the groups. Similarly, the IGFBP-3 levels are shown in Table $7 \mathrm{~b}$ for the seven AFC categories revealing similar mean and median levels around $165 \mathrm{nmol} / \mathrm{L}$ to $170 \mathrm{nmol} / \mathrm{L}$ across the groups. The pattern clearly fits a Normal distribution with virtually no skewness. The inter-quartile range is $145 \mathrm{nmol} / \mathrm{L}$ to $189 \mathrm{nmol} / \mathrm{L}$ without any significant variation across the AFC range of groups. Finally, the IGFBP-3/ IGF-1 ratios are shown in Table 7c. The IGF ratio ranges from minimum levels at 2.5 to 4.0 up to the highest maximum of 20.4 in a woman with AFC group D. The inter-quartile range is from 5.5 to 7.8 across the AFC groups A++ down to C and appears slightly higher at 6 to 8.4 for the lowest AFC categories, D and E; however, this slight elevation appears not significant. This data is further extended and displayed in Figure 7 with a Box and Whisker profile for the seven AFC Groups. These range from a high at AFC A++ with $\geq 40$ small antral follicles to a low at $\mathrm{AFC} E$ with $\leq 4$ small antral follicles.

The IGF-1 levels across the range are shown in Figure 7a and show no significant variation from $25 \mathrm{nmol} / \mathrm{L}$. Similarly, the mean IGFBP-3 levels in Figure 7b show no significant variation from $160 \mathrm{nmol} / \mathrm{L}$ to $170 \mathrm{nmol} / \mathrm{L}$ across the entire range of seven AFC groups. Finally, the mean IGF ratio of IGFBP-3/ IGF-1 shown in Figure 7c is 6.6-7.0 across the A to C groups, rising slightly to 7.2 and 7.4 in the $\mathrm{D}$ and E groups respectively, but these levels are all considered to be not significant.

\subsection{IGF profile Vs AMH}

Table 8 Summary statistics are shown for the 1633 women with IGF profiles stratified according to their AMH levels and further depicted in Figure 8. The distribution of IGF-1 levels is shown in Table 8a, the distribution of IGFBP-3 levels is shown in Table $8 \mathrm{~b}$ and the distribution of IGF ratios is shown in Table 8c.

Table 8a

\begin{tabular}{|l|l|l|l|l|l|l|l|}
\hline \multicolumn{6}{|l}{ IGF-1 nmol/L vs AMH Groups } & \multicolumn{7}{l|}{$l$} \\
\hline AMH Group & A++ & A & A & B & C & D & E \\
\hline N (women) & 354 & 128 & 171 & 233 & 248 & 265 & 234 \\
\hline Min IGF-1 & 10 & 11 & 14 & 9 & 11 & 10 & 8 \\
\hline Max IGF-1 & 63 & 44 & 44 & 49 & 42 & 50 & 52 \\
\hline Sum & 9446 & 3394 & 4483 & 6149 & 6226 & 6557 & 5452 \\
\hline Mean & 26.7 & 26.5 & 26.2 & 26.4 & 25.1 & 24.7 & 23.3 \\
\hline Std. error & 0.4 & 0.7 & 0.5 & 0.4 & 0.4 & 0.4 & 0.4 \\
\hline Variance & 54.0 & 55.5 & 34.9 & 46.0 & 36.3 & 50.5 & 45.3 \\
\hline Stand. dev & 7.3 & 7.4 & 5.9 & 6.8 & 6.0 & 7.1 & 6.7 \\
\hline Median & 26 & 25 & 25 & 26 & 25 & 24 & 23 \\
\hline $25^{\text {th }}$ centile & 22 & 22 & 22 & 22 & 21 & 20 & 19 \\
\hline $75^{\text {th }}$ centile & 31 & 32 & 30 & 30 & 29 & 29 & 27 \\
\hline Skewness & 0.8 & 0.6 & 0.5 & 0.3 & 0.3 & 0.5 & 0.7 \\
\hline Kurtosis & 1.9 & -0.2 & 0.1 & 0.9 & -0.1 & 0.5 & 1.4 \\
\hline Geom. mean & 25.7 & 25.5 & 25.6 & 25.5 & 24.4 & 23.7 & 22.4 \\
\hline Coeff. var & 27.5 & 28.1 & 22.5 & 25.7 & 24.0 & 28.7 & 28.9 \\
\hline
\end{tabular}


Table $8 b$

\begin{tabular}{|l|l|l|l|l|l|l|l|}
\hline \multicolumn{2}{|l}{ IGFBP-3 nmol/L vs AMH Groups } \\
\hline AMH Group & A++ & A & A & B & C & D & E \\
\hline N (women) & 354 & 128 & 171 & 233 & 248 & 265 & 234 \\
\hline Min IGFBP-3 & 59 & 89 & 94 & 107 & 96 & 73 & 66 \\
\hline Max IGFBP-3 & 265 & 245 & 253 & 270 & 250 & 263 & 240 \\
\hline Sum & 60337 & 21570 & 29162 & 39439 & 41318 & 43450 & 38476 \\
\hline Mean & 170.4 & 168.5 & 170.5 & 169.3 & 166.6 & 164.0 & 164.4 \\
\hline Std. error & 1.6 & 2.8 & 2.3 & 1.9 & 1.7 & 1.8 & 1.9 \\
\hline Variance & 954.8 & 981.7 & 875.9 & 819.9 & 711.0 & 871.6 & 839.4 \\
\hline Stand. dev & 30.9 & 31.3 & 29.6 & 28.6 & 26.7 & 29.5 & 29.0 \\
\hline Median & 167.5 & 169.5 & 167 & 165 & 165 & 166 & 162 \\
\hline 25 $5^{\text {th }}$ centile & 149 & 149 & 151 & 151 & 149 & 144 & 146 \\
\hline $75^{\text {th }}$ centile & 191 & 189 & 188 & 186 & 183 & 182 & 183 \\
\hline Skewness & 0.2 & 0.1 & 0.4 & 0.6 & 0.3 & 0.1 & -0.1 \\
\hline Kurtosis & 0.3 & -0.2 & 0.3 & 0.5 & 0.5 & 0.4 & 0.5 \\
\hline Geom. mean & 167.6 & 165.5 & 168.0 & 166.9 & 164.5 & 161.2 & 161.7 \\
\hline Coeff. var & 18.1 & 18.6 & 17.4 & 16.9 & 16.0 & 18.0 & 17.6 \\
\hline
\end{tabular}

Table 8c

\begin{tabular}{|l|l|l|l|l|l|l|l|}
\hline \multicolumn{6}{|l}{ IGFBP-3/ IGF-1 Ratio vs AMH Groups } \\
\hline AMH Group & A++ & A+ & A & B & C & D & E \\
\hline N (women) & 354 & 128 & 171 & 233 & 248 & 265 & 234 \\
\hline Min IGF Ratio & 3.4 & 2.5 & 4 & 3.3 & 3.5 & 3.3 & 2.6 \\
\hline Max IGF Ratio & 14.2 & 12.7 & 11.1 & 16.8 & 13.6 & 15.6 & 20.4 \\
\hline Sum & 2371.5 & 856.1 & 1143.3 & 1569.1 & 1719.5 & 1864 & 1759.8 \\
\hline Mean & 6.7 & 6.7 & 6.7 & 6.7 & 6.9 & 7.0 & 7.5 \\
\hline Std. error & 0.1 & 0.1 & 0.1 & 0.1 & 0.1 & 0.1 & 0.1 \\
\hline Variance & 2.6 & 2.7 & 1.6 & 3.0 & 2.8 & 3.9 & 4.9 \\
\hline Stand. dev & 1.6 & 1.6 & 1.3 & 1.7 & 1.7 & 2.0 & 2.2 \\
\hline Median & 6.5 & 6.4 & 6.6 & 6.4 & 6.8 & 6.6 & 7.2 \\
\hline 25 centile & 5.6 & 5.6 & 5.7 & 5.6 & 5.8 & 5.7 & 6.1 \\
\hline $75^{\text {th }}$ centile & 7.5 & 7.6 & 7.6 & 7.4 & 8.0 & 7.8 & 8.6 \\
\hline Skewness & 1.0 & 0.8 & 0.5 & 1.6 & 1.0 & 1.4 & 1.6 \\
\hline Kurtosis & 1.6 & 1.4 & 0.1 & 5.2 & 2.1 & 2.7 & 6.1 \\
\hline Geom. mean & 6.5 & 6.5 & 6.6 & 6.5 & 6.7 & 6.8 & 7.2 \\
\hline Coeff. var & 24.0 & 24.5 & 18.8 & 25.8 & 24.0 & 28.1 & 29.4 \\
\hline
\end{tabular}




\section{Figure 8a}

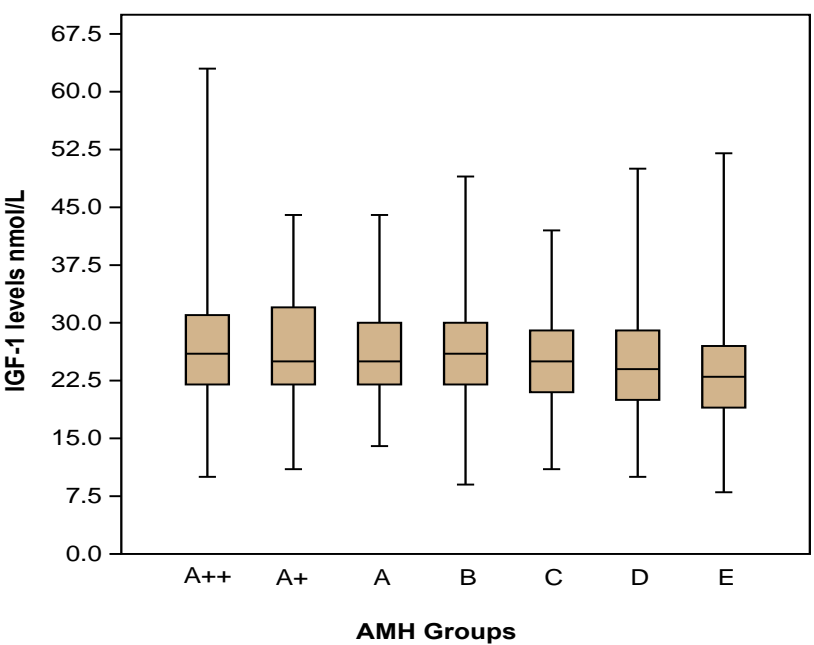

Figure 8b

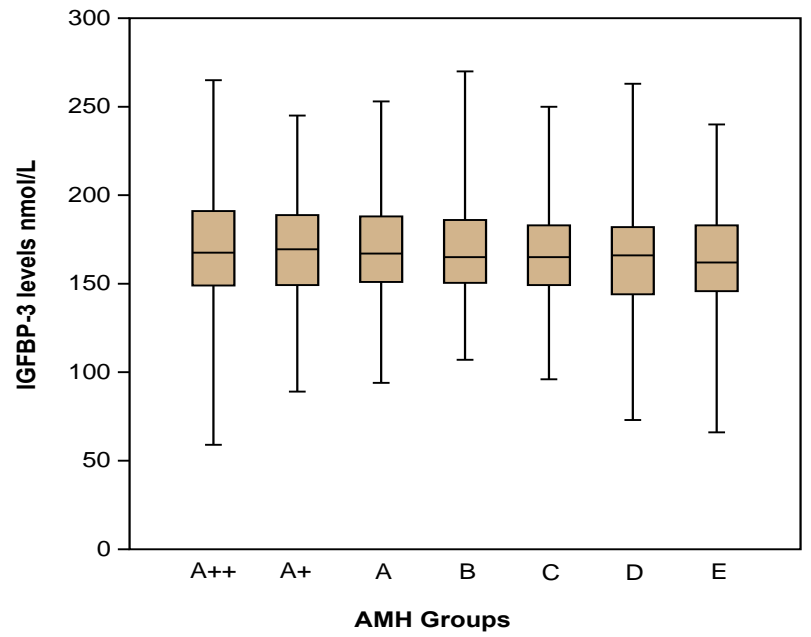

Figure 8c

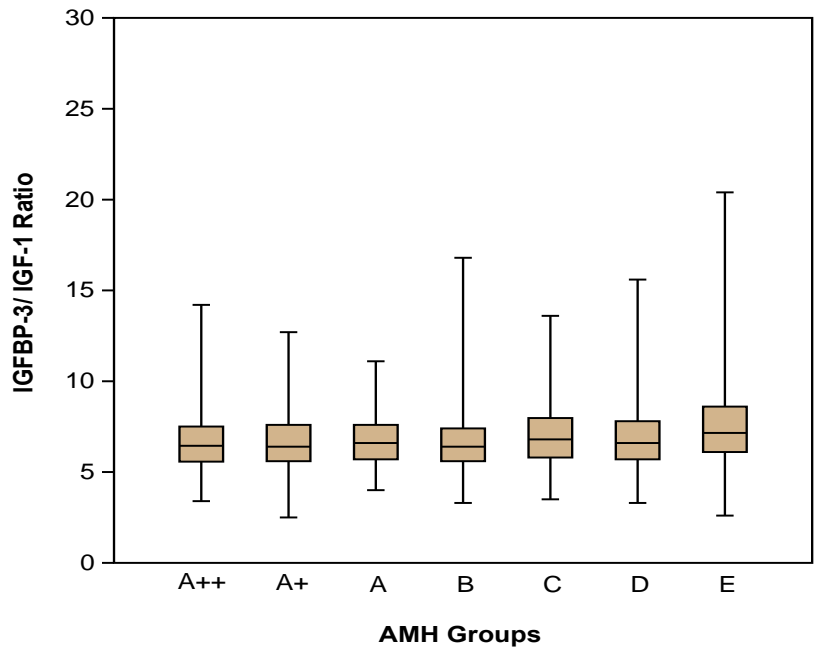

Figure 8 Depicts a box and whisker profile for the seven AMH groups ranging from a high at AMH A++ (>30 pmol/L) to a low at $\mathrm{AMH}$ group $\mathrm{E}(<5 \mathrm{pmol} / \mathrm{L})$; some of the latter being below the assay detection point. These are each profiled against the range of IGF-1 levels in Figure 8a, the IGFBP-3 levels in Figure 8b and the IGF ratios in Figure 8c. 
The IGF-1 levels are shown for seven AMH categories ranging from the highest at Group A++ with levels $>30$ pmol/L to the lowest at Group E with $<5 \mathrm{pmol} / \mathrm{L}$, some of which were below the assay detection point. Table 8a covers the IGF-1 component of the IGF profile. It can be seen that both mean and median IGF-1 levels are similar at around $25.5 \mathrm{nmol} / \mathrm{L}$. This is consistent with a Normal Distribution for IGF-1 which was shown in Study 1 [10]. There is minimal skewness, and the inter-quartile range is quite narrow across the groups, being mostly $21 \mathrm{nmol} / \mathrm{L}$ to $32 \mathrm{nmol} / \mathrm{L}$ with no significant differences across the groups. Similarly, the IGFBP-3 levels are shown in Table $8 \mathrm{~b}$ for the seven AFC categories revealing similar mean and median levels around $165 \mathrm{nmol} / \mathrm{L}$ to $170 \mathrm{nmol} / \mathrm{L}$ across the groups. The pattern clearly fits a Normal distribution with virtually no skewness. The inter-quartile range is $145 \mathrm{nmol} / \mathrm{L}$ to $189 \mathrm{nmol} / \mathrm{L}$ without any significant variation across the AMH range of groups. Finally, the IGFBP-3/ IGF-1 ratios are shown in Table 8c. The IGF ratio ranges from minimum levels at 2.5 to 4.0 up to the highest maximum of 20.4, measured in a woman with AFC group E. The inter-quartile range is from 5.5 to 7.8 across the $\mathrm{AMH}$ groups $\mathrm{A}++$ down to $\mathrm{C}$ and appears slightly higher at 6 to 8.4 for the lowest $\mathrm{AMH}$ categories D and E; however, this slight elevation appears not significant as shown in Figure 8.

The IGF-1 levels across the range are displayed in Figure 8a and show no significant variation from $\sim 25 \mathrm{nmol} / \mathrm{L}$. Similarly, the mean IGFBP-3 levels depicted in Figure 8b show no significant variation from $165 \mathrm{nmol} / \mathrm{L}$ to $170 \mathrm{nmol} / \mathrm{L}$ across the entire range of seven AMH groups. Finally, the mean IGF ratio of IGFBP-3/ IGF-1 shown in Figure 8c is 6.7 across the A to B groups, rising slightly to 7.0 at Group $C$ then 7.2 and 7.4 in the $\mathrm{D}$ and E groups respectively, but these slightly elevated levels are all considered to be not significantly different across the full range.

\section{Discussion}

This study is the second in a series towards the development of a clear identification of the woman who is likely to benefit from the use of GH as an adjuvant in ART management. This requires an understanding of the factors impacting on the IGF/GH axis [9] and the limitations of measurement of the various parameters applied in the identification of women categorised as having a poor prognosis. The latter can be due to a range of fertility factors, namely:

Ovarian - ranging from diminished ovarian reserve, poor ovarian response to ovarian stimulation and ovaries damaged by disease (mainly pelvic endometriosis and pelvic inflammatory disease) or surgeries (designed to correct the diseases).

Endometrium - ranging from poor endometrial development, inadequate hormonal stimulation of the endometrium and uterine damage from disease (mainly endometrial polyps, uterine adenomyosis and uterine leiomyomata) and surgeries (designed to correct the diseases as well as curettage procedures for complicated pregnancies).

Embryo disorders - secondary to disorders of the gametes (both spermatozoa and oocytes) and includes aneuploidies, specific genetic conditions including translocations, and simply poor embryo development in culture.

Unclear reasons - these might relate to nutritional disorders in either partner as well as lifestyle factors including the influence of advanced age, especially related to the female. Furthermore, the likelihood of environmental pollutants, increasingly linked to endocrine disruption, may be a significant modern factor.

Whilst all the above bear consideration, the therapeutic tools are limited hence the application of a wide array of adjuvants, numbering more than fifty, have emerged; so far none of them having high-level evidence-based confirmation $[3,4]$. The only one with moderate support is that of GH [7], but identification of the individual likely to benefit requires an understanding of the IGF/GH axis and the complex interaction of the relevant impacting factors.

To this end PIVET has commenced the undertaking of a series of studies designed to identify those women who might have AGHD. A number of retrospective studies have been reported from PIVET which demonstrate the possibility of GH benefit in some women labelled as poor-prognosis [6]. The first analytical study has recently been reported [10] and shows a significant linear reduction in IGF-1 levels across the four age groups ( $<35$ years, 35-39 years, 40-44 years and $\geq 45$ years. However, there was no variation in IGFBP-3 levels but the IGF Ratio showed a progressive linear elevation with advancing age. We had shown that both IGF-1 and IGFBP-3 were continuous variables and distributed in a normal fashion, hence amenable to parametric analysis. With respect to both BMI and stature, none of the IGF profile parameters showed any variation. This second study progresses to an examination of the IGF profile into those parameters which have emerged as representative of the ovarian reserve, namely the AFC determined by transvaginal ultrasound scanning, and the AMH levels measured from the woman's serum. These studies have been undertaken on women who presented to the PIVET clinic with a view to ART, but who have consented to undertake preliminary studies in an $\mathrm{AC}$ prior to any therapeutic intervention. 
The main findings shown in the results can be summarised as:

The AFC data showed highly significant, sequential changes across the 4 age groups with high counts in the younger women and significantly lower counts in the older women $(\mathrm{p}<0.0001)$.

AMH levels also showed highly significant sequential changes across the 4 age groups with high levels recorded in the young women and low counts in the older women $(\mathrm{p}<0.0001)$.

When AMH groups were compared with AFC groups, there was a high concordance demonstrated. For the higher AFCs groups, precise concordance was demonstrated at the rate of $79 \%$, rising to $95 \%$ when the neighbouring groups were included. At the lower AFC groupings, precise concordance was $69 \%$, rising to $88 \%$ respectively.

The correlation between AMH levels and AFC groups is clearly related with mean AMH levels ranging from 27 pmol/L to $49.9 \mathrm{pmol} / \mathrm{L}$ in the AFC groups "A" declining sequentially to levels of 8.1 to 10.4 in the D and E groups respectively $(\mathrm{p}<0.0001)$.

IGF profiles (namely IGF-1 levels, IGFBP-3 levels and the IGF Ratio) showed no significant variation across the entire range of AFC groups.

IGF profiles (namely IGF-1 levels, IGFBP-3 levels and the IGF Ratio) showed no significant variation across the entire range of $\mathrm{AMH}$ groups.

The measurement of IGFBP-3 levels in itself provided no clear benefit over that of the measurement of IGF-1 levels, neither for AFC nor for AMH comparisons.

The measurement of the IGF Ratio, (being IGFBP-3 / IGF-1) may have some benefit in expression, being most tightly expressed in the inter-quartile range from 5.5 to 8.0 .

Although the IGF-1/GH axis has been reported as essential for folliculogenesis and oocyte maturation, outside our own studies, there have been only a few reports in the last two decades attempting to examine the IGF-1 role in ART [16,17]. Separate studies recently reported from the Cornell Weill Medical Institute in New York, examined the serum IGF-1 relevance in women with variable responses to ovarian stimulation, along with the influence of estrogen therapy on that profile [17]. Some of the reported results, include unfavourable outcomes in those women with high IGF-1 levels appear surprising according to our own, as yet unpublished, clinical studies, and certainly bears review with a separate analysis. The results reported in this second study from PIVET, when combined with those of the first study, provide a basis to proceed further by next examining the relationship of the IGF-1 level and the IGF Ratio to clinical outcomes, bearing in mind the need to adjust the analysis for age of the female. However, body weight, stature and BMI were shown not to be relevant factors.

\section{Conclusion}

At PIVET in Perth, Australia, we have been undertaking a series of studies examining the IGF profile with a view to determine if there is an underlying clinical problem of AGHD causing the poor-prognosis outcomes for some women in ART programmes. In children GHD is likely when stature is under the $5^{\text {th }}$ centile for age and IGF- 1 levels are seen to be low, usually with an elevated IGFBP-3/IGF-1 Ratio $>5.0$. The definitive diagnosis of GHD requires a sub-optimal response to a provocative challenge test, usually undertaken by an endocrinologist in a hospital setting. Sequentially, it is our plan to carefully follow this approach to determine AGHD in sub-fertile women attending for ART. Our first reported study shows that the IGF profile is significantly influenced by the woman's age, but neither by her stature nor her BMI level. This second study shows no variation of the IGF profile across the full range of AMH and AFC groups according to the PIVET FSH-dosing Algorithms as long as the studies take into account the woman's age as both of the parameters for ovarian reserve show significant declines with rising female age. With these fundamental studies completed, our plan is to next investigate the relevance of the IGF profile to clinical outcomes, prior to embarking on GH-related studies. 


\section{Compliance with ethical standards}

\section{Acknowledgments}

We are grateful for the close working relationship between PIVET ${ }^{\circledR}$ Medical Centre and CLINIPATH ${ }^{\circledR}$ Pathology which carried out the assays involved in the IGF profile.

\section{Disclosure of conflict of interest}

The entire project has been funded internally at PIVET without any external or commercial contributions. The authors declare no conflict of interest.

\section{Statement of ethical approval}

Reporting of the data was approved under Curtin University Human Ethics Committee approval no. RD_25-10 general approval for retrospective data analysis in 2010, updated in 2015, and again further updated recently, in August 2020.

\section{Statement of informed consent}

PIVET is accredited with both the self-regulatory National Australian Reproductive Technology Committee (RTAC) as well as the Reproductive Technology Council (RTC) of Western Australia. Consent forms received approval under both regulatory bodies.

\section{Author Contributions}

The study was conceived by PIVET Medical Director JLY who established the data base at PIVET Medical Centre with the assistance of IT Consultant and data manager PMH. The first data extractions were undertaken by SZ who was on a sabbatical study period from her facility in Malaysia to which she has now returned. The Data has been further analysed by PMH supported by MDKN who has a managerial role for the Laboratory Assays at PIVET. All authors have assisted with the data analyses as well as the preparation of the Tables and Figures. The manuscript was written by JLY and each of the authors have read and agreed to its content.

\section{References}

[1] Yovich JL, Craft IL. Founding pioneers of IVF: Independent innovative researchers generating livebirths within 4 years of the first birth. Reprod Biol, 2018; 18:317-323, doi.org/10.1016/J.repbio.2018.11.004

[2] Yovich JL. Founding pioneers of IVF Update: Independent innovative researchers generating livebirths within 4 years of the first birth. Reprod Biol, 2020; 20:111-113, doi.org/10.1016/j.repbio.2019.12.008

[3] Yovich JL, Ye Y, Regan SLP, Keane KN. The evolving concept of poor-prognosis for women undertaking IVF and the notion of growth hormone as an adjuvant; a single-center viewpoint. Front Endocrinol, 2019; 10:808; pp14, doi.org/10.3389/fendo.2019.0080

[4] Farquhar C. Add-ons for assisted reproductive technology: can we be honest here? Fertil Steril, 2019; 112(6):971-972. doi.org/10.1016/j.fertnstert.2019.10.010

[5] Regan SLP, Knight PG, Yovich JL, Arfuso F, Dharmarajan A. Growth hormone during in vitro fertilization in older women modulates the density of receptors in granulosa cells, with improved pregnancy outcomes. Fertil Steril, 2018; 110:1298-309, doi: 10.1016/j.fertnstert.2018.08.018

[6] Yovich JL, Regan SL, Zaidi SN, Keane KN. The concept of growth hormone deficiency affecting clinical prognosis in IVF. Front Endocrinol, 2019; 10:650, Pp9, doi: 10.3389/fendo.2019.00650

[7] Bortoletto P, Spandorfer S. Growth hormone: in search of the holy grail for poor responders (or a felony). Fertil Steril, 2020; 114(1):63-64, doi.org/10.1016/j.fertnstert.2020.04.012

[8] Stanley T. Diagnosis of growth hormone deficiency in childhood. Curr Opin Endocrinol Diabetes Obes, 2012; 19(1):47-52, doi:10.1097/MED.0b013e32834ec952

[9] Ipsa E, Cruzat VF, Kagize JN, Yovich JL, Keane KN. Growth Hormone and insulin-like growth factor in reproductive tissues. Front Endocrinol, 2019; 10:777, pp14, doi: 10.3389/fendo.2019.00777 
[10] Yovich JL, Zaidi S, Nguyen MDK, Hinchliffe PM. Measuring IGF-1 and IGFBP-3 profiles in women seeking assisted reproduction; relationship to clinical parameters (Study 1). J Pers Med, 2020; 10(3)122:1-15, doi.org/10.3390/jpm10030122

[11] Yovich JL. How to prepare the egg and embryo to maximise IVF success. In: Monitoring the stimulated IVF cycle. Section II: Stimulation for IVF (Eds: Gabor T Kovacs, Anthony J Rutherford and David K Gardner). Cambridge University Press, Cambridge U.K., 2019; 94-120, doi: 10.1017/9781316756744

[12] Yovich J, Stanger J, Hinchliffe P. Targeted gonadotrophin stimulation using the PIVET algorithm markedly reduces the risk of OHSS. Reprod Biomed Online, 2012; 24(3):281-292, doi:10.1016/j.rbmo.2011.11.014

[13] Yovich JL, Alsbjerg B, Conceicao JL, Hinchliffe PM, Keane KN. (2016). PIVET rFSH dosing algorithms for individualized controlled ovarian stimulation enables optimized pregnancy productivity rates and avoidance of ovarian hyperstimulation syndrome. Drug Des Devel Ther, 10, 2561-573, doi: 10.2147/DDDT.S104104

[14] Keane K, Cruzat VF, Wagle S, Chauhary N, Newsholme P, Yovich J. Specific ranges of anti-Mullerian hormone and antral follicle count correlate to provide a prognostic indicator for IVF outcome. Reprod Biol, 2017; 17:51-59, doi.org/10.1016/j.repbio.2016.12.002

[15] Hammer $\emptyset$, Harper DAT, Ryan PD. PAST: paleontological statistics software package for education and data analysis. Palaentologia Electronica, 2001; 4(1): 9pp

[16] Nasioudis D, Minis E, Irani M, Kreines F, Witkin SS, Spandorfer SD. Insulin-like growth factor-1 and soluble FMSlike tyrosine kinase-1 prospectively predict cancelled IVF cycles. J Assist Reprod Genet, 2019; 36(12):2485-2491, doi: 10.1007/s10815-019-01618-3.

[17] Man L, Lekovich J, Canon C, Rosenwaks Z, James D. Cycle day-2 insulin-like growth factor-1 serum levels as a prognostic tool to predict controlled ovarian hyperstimulation outcomes in poor responders. Fertil Steril, 2020; 113:1205-1214, doi.org/10.1016/j.fertnstert.2020.02.111 